\title{
The research progress on food organism culture and technology utilization in crab seed production in ponds in China
}

\author{
Jibing $\mathrm{Qi}^{1,2}$, Xiaolian $\mathrm{Gu}^{2 *}$, Lingbo $\mathrm{Ma}^{2}$, Zhenguo $\mathrm{Qiao}^{2}$, Kai Chen ${ }^{2}$ \\ ${ }^{1}$ Institute of Aquaculture and Life, Shanghai Ocean University, Shanghai, China \\ ${ }^{2}$ East China Sea Fishery Research Institute, Chinese Academy of Fishery Science, Shanghai, China; \\ *Corresponding Author: guxl@mail.eastfishery.ac.cn, xlgu_1972@hotmai.com
}

Received 23 April 2013; revised 24 May 2013; accepted 25 June 2013

Copyright (C) 2013 Jibing Qi et al. This is an open access article distributed under the Creative Commons Attribution License, which permits unrestricted use, distribution, and reproduction in any medium, provided the original work is properly cited.

\begin{abstract}
Eriocheirsinensis, Portunus trituberculatus and Scylla paramamosain are important commercial culture crab species in China. Traditional factory breeding of crabs depends on Artemia nauplius. The rising price of Artemia cysts has led to the decline of the economic benefit of the crab breeding factory. Factory crab breeding has been gradually replaced by pond breeding in recent years. E. sinensis and $P$. trituberculatus have been bred mainly in ponds. Meanwhile, $S$. paramamosain is still mainly bred in factories because of the crudeness of pond breeding. The research progress on food organism utilization in the three species of commercially bred crabs was reviewed in this paper. In the workshop seeds production, rotifer and Artemia nauplii were necessary in the early stages from zoea I to zoea II in the three crab species. Adult artemia, minced fish and shellfish were fed to the larvae in the later zoea stages from zoea III to Megalopa. The rising of the price of artemia eggs made people find other feed organism to replace artemia. Copepods have been used in crab seeds production in pond from zoea III stage to replace artemia in recent years, which has reduced the cost of seeds production.
\end{abstract}

Keywords: Food Organisms; Crab Seeds; Ponds

\section{THE PRESENT SITUATION OF CRABS SEED PRODUCTION AND CULTURE IN CHINA}

Eriocheirsinensis, Portunus trituberculatus and Scylla paramamosain are the most commonly cultured crabs in China. According to the fishery statistics of China [1], culture area and annual output of three kinds of crabs in the whole country in 2009 were E. sinensis $466,700 \mathrm{hm}^{2}$ and $574,200 \mathrm{t}, P$. trituberculatus $31,800 \mathrm{hm}^{2}$ and $91,100 \mathrm{t}$ and S. paramamosain $30,700 \mathrm{hm}^{2}$ and $115,900 \mathrm{t}$. The total culture area and output were $529,200 \mathrm{hm}^{2}$ and 781,200 t, respectively. Crab culture has become one of the pillar industries in China's aquaculture industry.

The progress of aquaculture is based on offspring seed. In China, the production technology research on crabs' seed culture dates from the earlier stages of 1970s. Bushao Xu and Naigang Zhao were the first to conduct research on the seawater factory breeding of $E$. sinensis; subsequently, they pioneered the artificial breeding of $E$. sinensis $[2,3]$. By the end of the 1990s, E. sinensis factory breeding technology became mature and megalopa output per unit water body reached $0.1 \mathrm{~kg} / \mathrm{m}^{3}$ to 0.2 $\mathrm{kg} / \mathrm{m}^{3}$, and even more than $1 \mathrm{~kg} / \mathrm{m}^{3}$ [2]. Afterwards, factory-breeding technology was widely used in P. trituberculatus and S. paramamosain cultures. This promoted the rapid development of Chinese crab culture.

Since the 21 st century, with the development of breeding technology of E. sinensis and P. trituberculatus in ponds, production capacity has constantly improved and offspring seed production has increased year by year. In 2009, megalopa (M) output of E. sinensis and P. trituberculatus in the whole country reached approximately $78,7521 \mathrm{~kg}[1]$ and $8000 \mathrm{~kg}$ (800 million to 1 billion individuals), respectively [4].

\section{CRAB SEED PRODUCTION IN PONDS}

In factory seed production, larval rearing of crabs needs more controlled conditions, such as air supply, water supply, heat supply, and light control; thus, the cost of in- 
frastructure of the workshop and crab seed production is higher. In comparison, seed culture in ponds is low cost. Prior to breeding, cultureponds need to be cleaned and disinfected strictly; subsequently, they need to be fertilized and inoculated with unicellular algae. In the process of larval rearing, food organisms, such as rotifers and copepods, are necessary at different larval stages. Seed production cost is lower in ponds and has advantages in terms of popularization and promotion [5]. A seed production factory with $1000-\mathrm{m}^{3}$ water body workshop costs more than 300,000 RMB, while a pond farm with 6700$\mathrm{m}^{2}$ pond costs less than 70,000 RMB [5]. Seed production in ponds has become a main method of seed production of E. sinensis and P. trituberculatus, in China. The ratio between pondseed outputs and total outputs (including factory seeds, pond seeds and seeds captured from the sea) of E. sinensis and $P$. trituberculatus in China are over $95 \%$ and $70 \%$, respectively [4]. However, S. paramamosain seed production in ponds still needs further research. S. paramamosain seeds are still mainly produced in workshop, with an output less than 100 million individuals each year in China. S. paramamosain seeds mainly rely on natural seedlings in the sea [4].

\section{FOOD ORGANISMS OF THE LARVAL STAGE OF THREE CRAB SPECIES}

\subsection{Food Organisms in Zoea and Megalopa Stage of Three Crab Species}

The quality and quantity of food is the key of the crab larval culture. The research of food used in crab breeding began in the 1990s. Under experimental conditions, Zhaoshu Zeng et al. (1992) only used rotifer or Artemia nauplii to feed $S$. paramamosain larvae, studying the metamorphosis rate and survival rate of Zoea $I\left(Z_{1}\right)$ to Zoea $V\left(Z_{5}\right)$, in order to determine which food items are suitable at zoea stages [6]. The results showed that during $Z_{1}$ stage, the survival rate of the larvae, which were only fed with Artemia nauplii, significantly declined. This result could indicate that Artemia nauplii were too large to be caught by the larvae of $S$. paramamosain at the $Z_{1}$ stage [6]. From the stages $Z_{4}$ to $Z_{5}$, if larvae were only fed with rotifer, only few larvae could become megalopa and their survival rate would be very low. They also found that when rotifer density exceeds $10 \mathrm{ind} / \mathrm{ml}$, $Z_{1}$ could molt and develop into $Z_{2}$. Additionally, the survival rate of larvae increased along with rotifer density increasing from $20 \mathrm{ind} / \mathrm{ml}$ to $60 \mathrm{ind} / \mathrm{ml}$ [6]. Therefore, during $Z_{1}$ and $Z_{2}$ stage, $S$. paramamosain in factory breeding were fed with rotifer at appropriate density from $20 \mathrm{ind} / \mathrm{ml}$ to $30 \mathrm{ind} / \mathrm{ml}$ considering the dissolved oxygen and water quality. $Z_{3}$ was the important transitional phase of food organisms changing from rotifer to
Artemia nauplii. The larvae of $\mathrm{Z}_{3}$ were fed with Artemia nauplii and rotifer. From $\mathrm{Z}_{4}$ to $\mathrm{M}$, larvae were mainly fed with Artemia nauplii. The aforementioned food items were regarded as appropriate for larvae rearing in the factory [6]. Food items of E. sinensis, S. paramamosain, and $P$. trituberculatus have been studied by many researchers; subsequently, their findings have been applied to industry standards or local standards for the production of the three species crabs in China (Table 1) [7-9].

\subsection{Difference in food Organism Demands of Zoea Stages of Three Crab Species}

Under the experimental conditions, Mengzhong Gong (1998) compared the metamorphosis and survival rate of $S$. paramamosain and $P$. trituberculatus fed with different types of food, including 3 species of unicellular algae (Nannochloris oculata, Chaetoceros muelleri and Dicrateria inornata), three zooplanktons (rotifer, Artemia nauplii and copepods), and artificial food substitutes (soybean milk, egg yolk, shrimp mince and prawn larvae) [10]. He found that thelarvae of $S$. paramamosain could only finish metamorphosis from $\mathrm{Z}_{1}$ to $\mathrm{Z}_{2}$ stages, as all larvae perished after nine days. Meanwhile, $3 \%$ of $P$. trituberculatus larvae could develop to the megalopa stage when fed with mixed food substitutes (mix of soybean milk, egg yolk, shrimp mince and prawn larvae) [10]. The survival rates of $S$. paramamosain and P. trituberculatus from $\mathrm{Z}_{1}$ to $\mathrm{M}$ were $32 \%$ and $51 \%$, respectively, fed on the mix of rotifer and Artemia nauplii. The survival rates of the larvae of the two crabs were evidently lower when fed with rotifer or Artemia nauplii separately [10]. The survival rates of $S$. paramamosain and $P$. trituberculatusfrom $\mathrm{Z}_{1}$ to $\mathrm{M}$ were $54 \%$ and $63 \%$, respectively, when larvae were fed with algae, rotifer, Artemia nauplii and copepods by turns according to the stages. Research also showed that when larvae of two crabs in $\mathrm{Z}_{1}$ were fed with unicellular algae (Nannochloris oculata, Chaetoceros muelleri and Dicrateria inornata), 1\% larvae of $P$. trituberculatus developed to megalopa, while larvae of $S$. paramamosain all died during the first 10 days.

In the three species of crabs, the larvae of $E$. sinensis were the easiest to rear. Larvae of $Z_{1}$ and $Z_{2}$ in $E$. sinensis could be cultured with unicellular algae, a certain amount of egg yolk andbeer yeast (Saccharomyces cerevisiae). Meanwhile, larvae of $\mathrm{Z}_{3}$ are fed with Artemia nauplii, freezing copepods, cladocerans or artificial food [10-12].

\section{COMPOSITION AND FUNCTION OF FOOD ORGANISMS IN CRABS SEED PRODUCTION PONDS}

E. sinensis was the first crab species bred in ponds. Several research reports were available about the keys to breeding technology in ponds, such as composition and 
Table 1. Food items in stages of zoea and megalopa in E. sinensis, P. trituberculatus and S. paramamosain in factory breeding.

\begin{tabular}{|c|c|c|c|}
\hline & Eriocheirsinensis & Portunus trituberculatus & Scylla paramamosain \\
\hline $\mathrm{Z}_{1}$ & $\begin{array}{l}\text { Rotifer*, unicellular algaeEgg yolk, } \\
\text { Spirulina powder, Clamworm larvae }\end{array}$ & Unicellular algae, rotifer & Unicellular algae, rotifer \\
\hline $\mathrm{Z}_{2}$ & $\begin{array}{c}\text { Rotifer }^{* *}, \text { unicellular algae, } \\
\text { Artemia nauplii }\end{array}$ & $\begin{array}{l}\text { Unicellular algae, rotifer, } \\
\text { Artemia nauplii }\end{array}$ & $\begin{array}{l}\text { Rotifer }^{* *} \text {, unicellular algae, } \\
\text { Artemia nauplii }\end{array}$ \\
\hline $\mathrm{Z}_{3}$ & $\begin{array}{l}\text { Rotifer, Artemia nauplii**, } \\
\text { Egg yolk, Spirulina powder }\end{array}$ & $\begin{array}{l}\text { Artemia nauplii* } \\
\text { Artifical compound feed }\end{array}$ & $\begin{array}{l}\text { Artemia nauplii, Shrimp flakes, } \\
\text { Spirulina powder }\end{array}$ \\
\hline $\mathrm{Z}_{4}$ & $\begin{array}{l}\text { Artemia nauplii }{ }^{* *} \text { Copepods, Clamworm larvae, } \\
\text { Minced fish, Egg custard, Artifical compound feed }\end{array}$ & $\begin{array}{l}\text { Artemia nauplii }{ }^{* *} \\
\text { Artifical compound feed }\end{array}$ & $\begin{array}{l}\text { Artemia naupliiं }{ }^{* *} \text {, Shrimp flakes, } \\
\text { Spirulina powder }\end{array}$ \\
\hline $\mathrm{Z}_{5}$ & $\begin{array}{l}\text { Artemia nauplii** }{ }^{* *} \text { Clamworm larvae, Minced fish, } \\
\text { Egg custard, Artifical compound feed, }\end{array}$ & $*$ & $\begin{array}{l}\text { Artemia nauplii**, Shrimp flakes, } \\
\text { Spirulina powder }\end{array}$ \\
\hline M & $\begin{array}{l}\text { Artemia nauplii (or adult), Copepods, } \\
\text { Cladoceran Artifical compound feed }\end{array}$ & $\begin{array}{l}\text { Artemia nauplii (or adult), Copepods, } \\
\text { Cladoceran Artifical compound feed }\end{array}$ & $\begin{array}{l}\text { Artemia nauplii**, } \\
\text { Minced shellfish }\end{array}$ \\
\hline
\end{tabular}

Note: ${ }^{*}$ : there are only 4 zoea stages in P. trituberculatus, ${ }^{* *}:$ it means that larvae take them as main food.

function of the food organisms, suitable density, and predation ability of the larvae in different stages $[13,14]$.

Organisms in the ponds of crab seed production are made up of plankton and benthos. The plankton community is important in crab breeding because they comprise the food organisms of crab larvae. Research on the cluster, swimming and phototaxis of ecological habitat of food organisms, including rotifer, copepods and unicellular algae, and the relation between plankton and crabs zoea, are helpful to maintain the balance between food organisms and crab larvae in breeding ponds, which can be done through fertilizing, adding seawater, inoculating rotifer and supplementing copepods [13].

\subsection{Phytoplankton in the Ponds of Crab Breeding}

In ponds of crab breeding, the ideal phytoplankton is made up of different unicellular algae, such as marine chlorella, golden algae, Phaeodactylum triconutum and Nitzschia closterium. Marine chlorellais the best food for rotifer, whilegolden algae and diatoms can be eaten directly by the crab larvae in earlier stages. These algae can offer necessary nutrition to crab larvae directly or indirectly, especially highly unsaturated fatty acids of EPA (20:5n3) and DHA (22:6n3), which are necessary for crab larvae growth and development. Therefore, suitable unicellular algae density in ponds of crab breeding plays an important role for the high survival rate of early larvae. Furthermore, photosynthesis of algae can increase dissolved oxygen and absorb nitrogen and phosphorus in the water to maintain stability of the ecosystems in ponds $[13,15]$.

Algae of culture ponds presents diversity and varied trends, which are caused by many factors, such as light, temperature, nutrient salt and the quantity and kinds of zooplankton. In earlier stages of culture, ponds with fresh water have high abundance of algae, and the main algae are diatoms without flagellum. In the middle and later periods, with increasing amount of organic matter, flagellum algae that like organic matter become dominant species and other algae decrease $[13,16]$.

Qing Liu (2000) studied phytoplankton in ponds of culture rotifer and found that with on-going culture, the phytoplankton biomass decreased, biodiversity increased, small phytoplankton species decreased, and large phytoplankton species increased [17].

Algae community composition in ponds is often affected by pond clearing and disinfecting drugs. Changfa Liu (1998) studied the effect of bleaching powder on cleaning ponds and water quality of shrimp ponds, and subsequently proposed that the density of $30 \mathrm{mg} / \mathrm{L}$ bleaching powder could basically kill most plankton and bacteria, could oxidize dead organisms and reducing substances, and had little influence on nutrient salt [18].

Xiaodong Li (2007) discovered that dominant algae in the earlier breeding stage were small algae, which had fast reproductive speed and shorter generation time. In this stage, low quantity of nitrogen and phosphorus, which lower water temperature, were helpful to the growth and reproduction of unicellular algae, such as chlorella, diatoms and golden algae. Meanwhile, high quantities of nitrogen and phosphorus led to chlorococoum to become dominant. The use of fertilizers with very low quantity ratio of nitrogen and phosphorus, or with only phosphate applied, led to an increasein the number of nitrogen-fixing blue green algae [13].

Applying organic fertilizer directly to breeding ponds brought about difficulty in regulation and control of unicellular algae because organic fertilizer contained much bacteria and organic detritus. Consequently, zooplankton started to reproduce antecedent to phytoplankton, such that it was easy to lead to zooplankton's excessively rapid growth, and a great quantity of phytoplankton were eaten by filter-feeding zooplankton. Subsequently, even if inorganic fertilizer was added again, phytoplankton had difficulty in reproducing again. Inoculating unicel- 
lular algae in ponds before breeding, such as marine chlorella, was helpful to maintain the dominant position of unicellular phytoplankton, and prolonged its exponential growth phase. Dominant chlorella could promote the reproduction of rotifer in earlier stages of breeding and prevent water to be polluted by dinoflagellates in the later stage. Inoculation density or feeding density of rotifer should be reasonably controlled in earlier stages of breeding in ponds, which is important to maintain a better phytoplankton community environment.

\subsection{Rotifers in the Ponds of Crab Breeding}

Rotifers are universally acknowledged as high quality initial feedfor seed culture in fish, shrimps and crabs. They have some characteristics, such as small individual size, slow swimming speed, rapid reproduction through the use of bioticorganisms (algae, bacteria, etc.), that make them a good food organism for the growth and development of crab larvae in the earlier stages. Culturing rotifers in earthen ponds in the southern coast of China has entered the stage of commercialization, which can supply enough rotifers stably all year-round for seed production in marine fishes, shrimps and crabs.

At present, the main rotifers used in marine seed culture in China are Brachionus plicatillis and B. roundifurrnis. Studies show that suitable culture temperatures for Brachionus Plicatillis and B. roundifurrnis are $21^{\circ} \mathrm{C}$ to $25^{\circ} \mathrm{C}$ and $30^{\circ} \mathrm{C}$, respectively, and their individual sizes are $150 \mu \mathrm{m}$ to $200 \mu \mathrm{m}$ and $80 \mu \mathrm{m}$ to $120 \mu \mathrm{m}$, respectively [19]. Thus, they are named as large rotifer and small rotifer in early articles, respectively. In the production of crab seed, large rotifer is usually used in breeding of $E$. sinensis and $P$. trituberculatus in the north coast of China, while small rotifer is mainly used in breeding of $S$. paramamosain in the south coast of China.

In ponds of crab breeding, especially $S$. paramamosain breeding, small rotifer is often used as initial feed before the $Z_{3}$ in early larvae stage. If rotifer density is too low in pond, the survival rate of crab larvae in earlier stage will decline for lack of enough initial feed. On the contrary, in the later stages, if rotifer density is too high in pond, rotifers will massively reproduce because individuals of rotifersare too small to be effectively caught and fed on by the larvae of $Z_{4}$ and the later stage [6]. Thus, it is very important to control rotifer density reasonably.

Yonghan Li (1985) found that the number of rotifers increased in logistic curve in the rotifer culture pond. The rising period maintained from three days to five days when the density rotifer was at $10 \mathrm{ind} / \mathrm{ml}$ and it maintained for about ten days when the density of rotifers was only at $1 \mathrm{ind} / \mathrm{ml}[20]$. For this reason, it is hard to managementwater quality if a large number of rotifers are leftin ponds after the stage of $\mathrm{Z}_{4}$ in $S$. paramamosain breeding in ponds. However, large rotifer is used as ini- tial feed in breeding of E. sinensis and P. trituberculatus, and their zoea larvae can become megalopa even if rotifers are used alone as food [21,22].

Qingjing Zhang (2001) determinedthat that the optimum density of large rotifer is $3 \mathrm{ind} / \mathrm{ml}$ to $5 \mathrm{ind} / \mathrm{ml}$ in the stage of $Z_{1}$ and $Z_{2}$, and $10 \mathrm{ind} / \mathrm{ml}$ to $20 \mathrm{ind} / \mathrm{ml}$ during the period from $Z_{3}$ to $Z_{5}$. He also found that higher rotifer density is not better-long-term densities of rotifer over $20 \mathrm{ind} / \mathrm{ml}$ bring about negative effects on the growth of crab larvae [23].

XiaoDong Li (2007) cultured crab seeds of E.sinensis in $30-\mathrm{m}^{2}(5 \mathrm{~m} \times 6 \mathrm{~m} \times 1 \mathrm{~m})$ experimental enclosures which were placed in $1500-\mathrm{m}^{2}$ marine culture ponds. In the whole process of culture, Artemia nauplii was not used, but the enclosures were fertilized and chlorella and rotifers were inoculated without the addition of other food organisms. Subsequently, Li found that the optimum inoculation density ofchlorella and rotifer in the nursery pond of $E$. sinensiswere $50 \times 10^{4} \mathrm{ind} / \mathrm{ml}$ and 2 $\mathrm{ind} / \mathrm{ml}$, respectively [13]. The maximum output of megalopa was 1021 gin a single experimental enclosure, which meant that the output per unit water body was 34 $\mathrm{g} / \mathrm{m}^{3}$ megalopa [13].

Xueshi Zhang (2011) reported the results of seed production test of $E$. sinensis under the condition of oxygen supply at the bottom of nursery pond. Rotifer was the single species of animal food that was fed to crab larvae during the whole period from $Z_{1}$ to $M$ [21]. Seawater in the pond was fertilized 3 days before breeding. Larvae mainly depended on the organisms that came from fertilization. A small amount of yeast was supplemented in the first two days at the beginning of $\mathrm{Z}_{1}$ stage. Starting the third day, hatching larvae were fed with rotifers until the megalopa stage. Total output of megalopa was 466.8 $\mathrm{kg}$ in six nursery ponds with a total area of $7223 \mathrm{~m}^{2}(1.8$ $\mathrm{m}$ water deep), which meant an average output of 35.9 $\mathrm{g} / \mathrm{m}^{3}[21]$.

Hanyou Liu (2008) used large rotifer as the biological food in Portunus trituberculatus breeding in ponds, and the inoculation density of rotifer was $1.8 \mathrm{ind} / \mathrm{ml}$. The supply of rotifer was according to the food intake by larvae [24]. We succeeded in culturing the seeds of $S$. paramamosain in ponds using small rotifer as initial food at the density of $2 \mathrm{ind} / \mathrm{ml}$ to $4 \mathrm{ind} / \mathrm{ml}$ before $Z_{3}$ stage in the Hainan Province in 2012 (unpublished).

\subsection{Utilization of Copepods to Replace Artemia Nauplii in the Ponds of Crabs Breeding}

In factory crab breeding in China, Artemia nauplii is the main biological food after the stage of $Z_{3}$. Most crab seed production factories use Artemia nauplii as biological food during the period from $Z_{3}$ to $Z_{4}$. With the increasing price of Artemia cysts in the international mar- 
ket after 2000, the cost in Artemia cysts accounts for the increasing proportion of seed production total cost, even up to $67 \%$, which has a strong impact on the economic benefits of crab larvae production factories [12]. The search for food sourcesable to replace Artemia nauplii, has become the focus of the seedproduction industry in the recent years.Crab breeding in ponds aimed at using copepods to replace expensive Artemia nauplii, which was the main food after $Z_{3}$ stage. It has achieved some results through research and practice by many reseachers; and these research results promote technological development of crab breeding in ponds.

Copepods are a good replacement for Artemia nauplii. Copepods are an important part of the zooplankton community in marine culture ponds. They are rich in nutrition, and reproduce rapidly in optimal temperature conditions. Theyare among the best biological foods in seed production of marine fishes and freshwater fishes.

However, copepods swim fast such thatthey are difficult to be caught and fed on by larvae in the earlier stages. Moreover, carnivorous copepods actively attack, catch and feed on other food organisms; thus, they are eliminated as harmful organism before $Z_{3}$ stage in the crab larvae culture $[13,25]$. ShuGuo Li (2001) took the lead in developing production seeds of $E$. sinensis, which did not use Artemia nauplii in ponds. He used yeast powder, egg yolk, algae powder and small amount of rotifers as food at stages of $Z_{1}$ and $Z_{2}$. Rotifers were fed mainly at the stage of $Z_{3}$. Copepods, cladocerans and minced fish, beside rotifers, were fed from $Z_{4}$ to $Z_{5}$. Adult $A r-$ temia were fed at the stage of M. Megalopa output reached $750 \mathrm{~g} / \mathrm{m}^{3}$ per unit of water body and breeding cost decreased by $40 \%$ [12]. This method of crab breeding still had some problems, such as water quality being difficult to control and high risk of incidence rate, because of the highdensity of larvae and food organisms, and the abundance of water exchange.

QingJing Zhang (2007) studied the effects of two dominant species of copepods Eurytemor affinis and Sinocalanus tenellus on the survival rate of crab larvae in nursery pond of $E$. sinensis in Liao river delta region of Panjin Liaoning Province. The results showed that two species of copepodsdecreased the survival rate of $Z_{1}$ larvae of the crab when the density of two species of copepods was over $500 \mathrm{ind} / \mathrm{L}$ in the ponds [14].

Qingjing Zhang (2007) found that $Z_{3}$ of E. sinensis could catch and feed on copepod nauplii, and the predation quantity increased with increasing nauplii density. The $Z_{5}$ and $M$ of $E$. sinensis could feed on adult copepods. However, he found that $Z_{5}$ and $M$ of $E$. sinensis had obvious differences in predation rate of the two species of copepods. The predation rates of $\mathrm{Z}_{5}$ to Eurytemor affinis and Sinocalanus tenellus were $57.2 \%$ to $63.3 \%$ and only $3.3 \%$ to $8.3 \%$, respectively, while predation rates of $\mathrm{M}$ to Eurytemor affinis and Sinocalanus tenellus were $71.1 \%$ to $87.5 \%$ and $9.2 \%$ to $8.3 \%$, respectively. The two species of copepods had similar movement velocities; the difference in predation rates might be connected with their mode of movement [14].

Kai Chen (2010) compared the effects of Artemia nauplii and copepod influence on growth and development of $S$. Paramamosian from $\mathrm{Z}_{4}$ to $\mathrm{M}$. The study showed that survival rates of larvae fed with copepods were $95.72 \%$ and $89.66 \%$ during the stage from $Z_{4}$ to $Z_{5}$ and $\mathrm{Z}_{5}$ to $\mathrm{M}$, respectively, which increased $1.07 \%$, and $6.09 \%$ respectively, in comparison with the survival rate of the larvae fed with Artemia nauplii [26].

We studied the feeding habit of S. paramamosain zoeas in different stages. We found that the combination of rotifers and copepods could replace traditional food combination of rotifers and Artemia nauplii in seed production of $S$. paramamosain. We carried out an experiment involving $S$. paramamosain breeding in ponds in Wenchang of Hainan Province in 2012. Rotifers were fed during stage of $Z_{1}$ and $Z_{2}$, as well as during the earlier stage of $Z_{3}$. Juvenile copepods, which were filtered through 80 -screen mesh,were added in the later stage of $Z_{3}$. In stage of $Z_{4}$, small size copepods were cast into nursery ponds alone. Finally, adult copepods were fed in the stage of $Z_{5}$ at density $4000 \mathrm{ind} / \mathrm{L}$ to $5000 \mathrm{ind} / \mathrm{L}$. Megalopa output was 200,000 in a $500-\mathrm{m}^{2}$ pond, the survival rate from $Z_{1}$ to $M$ was $13 \%$, and breeding cost decreased by $32 \%$ (unpublished).

\section{THE EVALUATION OF THE EFFECT OF PONDS SEED PRODUCTION AND FOOD ORGANISM UTILIZATION}

\subsection{Breeding and Culture of Adults in the Same Pond}

Since seed production of crabs in China broke through scale manufacture technology in the end of the 20th century, the modes of seed production have undergone factory breeding and pond breeding phases. In factory breeding, algae, egg yolk, algae powder, Artemia nauplii and frozencladocerans are usually used as food, and plenty of water needs to be exchanged to maintain water quality. Factory breeding method has advantages of high output per unit water body and being less affected by weather change. It has disadvantages of high production cost and the seeds being susceptible to diseases. Factory breeding has been replaced gradually by pond breeding in E. sinensis and Portunus trituberculatus in recent years.

S. paramamosain seeds are produced in factory at present because the technique of pond breeding for this species is still immature and needs to be studied further. We have made progress in the pond breeding for $S$. paramamosain seeds in 2012 (unpublished). We believe that 
S. paramamosain seeds will be produced in ponds in the future, with the improving breeding technique in ponds. The process of pond breeding often includes cleaning the bottom, disinfection, fertilization and inoculation of algae and rotifers. In terms of the actual production, two modes of pond crab breeding are mainly used: breeding and culturing adults in same pond and commercial breeding.

The mode of breeding and culturing adult crabs in the same pond has a characteristic of breeding in low density. Disinfection treatment and fertilization operation in ponds and seawater during the period of breeding are the same as general pond breeding. The differences are as follows: First, in the earlier stage of breeding, lower water level leaves space for the regulation and control of water quality. Second, seawater in ponds is disinfected and then, tea seed cakes are used with mass concentration at $8 \mathrm{~kg} / 667 \mathrm{~m}^{2}$ to make the seawater rich and kill harmful organisms. Third, larvae stocking density is within $10,000 \mathrm{ind} / \mathrm{m}^{3}$. Fourth, the water transparency is maintained at $35 \mathrm{~cm}$ to $40 \mathrm{~cm}$ with topdressing. Yeast and soya-bean milk are poured into ponds during $Z_{1}$ and $\mathrm{Z}_{2}$ stages, and rotifers and copepods are not supplemented during all zoea stages. Actual breeding and culture showed that the above mode could avoid the threat of culture ponds being polluted effectively because of breeding in low density and the little amount of food. The output of commodity crabs of $P$. trituberculatus was usually about $60 \mathrm{~kg} / 667 \mathrm{~m}^{2}$ and white shrimp output is 200 $\mathrm{kg} / 667 \mathrm{~m}^{2}$, which were the mix species cultured in Jiangsu province in China.

\subsection{Commercial Breeding}

The commercial breeding mode of production has been widely used in seed and adults culture in S. paramamosa. Existing research and production results showed that the larvae of $E$. sinensis could develop from $Z_{1}$ to $M$ if they feed on large rotifer [13]. It is supposed that the food coefficient for the feeding of crab larvae on rotifers is 4 [13]. Under the assumption that the target megalopa output in this mode of pond breeding is $10 \mathrm{~kg} / 667$ $\mathrm{m}^{2}$, a $40-\mathrm{kg}$ rotifer output is needed in the $667-\mathrm{m}^{2}$ nursery pond within the 20 -day seed production cycle. It is difficult to culture $40 \mathrm{~kg}$ of rotifers if the food supply solely depends on the natural productivity of the water body alone through fertilization and algae and rotifer inoculation, without rotifer supplement [13]. Additionally, in the process of breeding, the equilibrium relationship among algae, rotifers and crab larvae in water body is affected not only by abiotic factors, such as light and temperature, but also by biological factors, such as food chain relationship between the involved organisms. Thus, it is hard to maintain the equilibrium relationship between the organisms under condition of high productivity in breeding ponds. So, a mass of rotifers and Artemia nauplii has to be used in commercial breeding. Rotifer culture in ponds is quite developed in China at present such that it can sufficiently provide rotifers for the seed production industry.

Algae, yeast, Artemia nauplii, copepods, and cladocerans almost meet the needs of crab seed production in factory or in pond in E. sinensis, P. trituberculatus and $S$. paramamosain. For some crabs, however, for example, Charybdis feriatus, these food organisms still cannot achieve a beneficial effect. In this regard, further studies should be conducted to search for more suitable biological food and to examine the use of micro granule diets with comprehensive nutrition in crab culture.

\section{ACKNOWLEDGEMENTS}

This work was financially supported by Central Public Welfare Scientific Research Institutes' special funding for basic research project (NO.2011M10); and the Shanghai Committee of Science and Technology, China (No. DZ1909303).

\section{REFERENCES}

[1] Fishery Bureau in Ministry of Agriculture (2010) China fisheries year book. China Agriculture Press, Beijing.

[2] Han, B.Y. (1996) The technical questions and answers of high-yield aquaculture of Eriocheir sinensis. China Agriculture Press, Beijing.

[3] Zhao, N.G. (1980) Experiments on the artificial propagation of the woolly-handed crab (Eriocheir sinensis) in artificial sea water. Journal of Fisheries of China, 4, 95104.

[4] Gu, X.L. and Qiao, Z.G. (2012) Progress of the crab seed cultivation in earthen pond in China. Marine Fisheries, 34, 110-116.

[5] Zhu, Y.F. and Song, C.H. (2000) Some questions of Eriocheir sinensis breeding in ponds. Shandong Fisheries, 17, 32-34.

[6] Zeng, Z.S. and Li, S.J. (1992) Experimental studies of ecology of Juvenile scylla serrata I: Food has influence on survival and development of larvae. Transactions of the Chinese Crustacean Society, 3, 85-94.

[7] Chen, P., Yan, B.L., Cheng, J., Li, Y.H., Wan, Q., Cheng, Q.Y. and Zhang, S.S. (2007) Technical specifications of artificial propagation for Chinese mitten-handed crab. Aquiculture industry criteria, SC/T 1099.

[8] Ding, X.Y., He, Z.Y., Sun, Z., Xu, G.H. and He, F. (2003) No-enviromental pollution crab, part 1: Guideline of larva production technology. Local standard of Zhejiang, DB33/ T 395.1.

[9] Qiao, Z.G., Cai, Y.Q., Yu, Z.L., Yu, H.J. and Bi, S.C. (2004) Nuisanceless food: Technical criteria for Scylla paramamosain culture. Agricultural industry criteria, NY/T 5277. China Agriculture Press, Beijing.

[10] Gong, M.Z. (1998) Comparison on feed of larval crab 
Scylla serrata and Portunus trituberculatus. Journal of Oceanography in Taiwan Strait, 17, 16-21.

[11] Wang, B.Q. (1992) A test on Artificial breeding of Eriocheir sinensis in pond. Fisheries Science, 11, 7-9.

[12] Li, S.G. (2001) Artemia nauplii can be replaced by food organism in breeding of Eriocheir sinensis. Scientific Fish Farming, 9, 45.

[13] Li, X.D. (2007) Studies on theory and technology of the river crab (Eriocheir sinensis) culture with ecological methods. Ph.D. Thesis, Ocean University of China, Qingdao.

[14] Zhang, Q.J., Li, X.D., Zhu, H., Liu, X. and Li, Y.H. (2007) Relationships between copepods and Eriocheir sinensis larvae in ecological breeding ponds. Chinese Journal of Applied Ecology, 18, 174-178.

[15] Lv, Y.H., Yu, Z.L., Wang, J.G., Qiao, Z.G. and Zhang, S.F. (2009) Studies on application of nutritional enrichment materials to rearing larval Scylla paramamosain. Marine Fisheries, 31, 270-278.

[16] Mai, X.J., Huang, W.J., Ye, F.L., Li, Z.J., Liang, H.F., Wang, Y.X. and Lin, Z.Y. (2009) Science of healthy cultivation of prawn. China Ocean Press, Beijing.

[17] Liu, Q., Li, X.D., Liu, X., Zhou, Z.J., Zhang, S.L. and Liu, Y.H. (2000) Species composition and biomass of plankton in rotifer breeding ponds. Journal of Dalian Fisheries University, 15, 186-192.

[18] Liu, C.F., Ma, Y.X., Liu, S.Q. and Liu, H.Y. (1998) The effectiveness on bleaching powder on cleaning shrimp pond and its effect on the water quality. Journal of Fish- ery Sciences of China, 5, 123-125.

[19] Wang, Y. and He, Z.H. (2002) The research progress of live food culture for marine fishes and crustacean. Review articles of world aquaculture conference communication in 2002.

[20] Li, Y.H., Ding, J.H. and Xu, F.X. (1985) Studies on the distribution and hatching of resting eggs of rotifer in fish ponds. Acta Hydrobiologica Sinica, 9, 20-31.

[21] Zhang, X.S. (2011) A test on the application of the bottom micropore oxygen supply technology in Eriocheir sinensis breeding ponds. Journal of Aquaculture, 5, 7-8.

[22] Shanghai Han-Bao Bioengineering Limited Company (2006) The breeding technology of Portunus trituberculatus in earthen pond (volume one). Scientific Fish Farming, 10, 82-83.

[23] Zhang, Q.J. (2001) The preliminary study on ecosystem in breeding pond of Eriocheir sinensis. Ph.D. Thesis, Dalian Fisheries College, Dalian.

[24] Liu, H.Y. (2008) The study on the breeding technique of Portunus trituberculatus in earthen pond. Hebei Fisheries, 6, 33-34.

[25] Wang, J.G., Qiao, Z.G. and Yu, Z.L. (2006) Experiment on the Use of Dipterex to Eradicate Copepod in the Rearing of Rotifier. Marine Fisheries, 28, 83-86.

[26] Chen, K., Qiao, Z.G. and Wang, C.X. (2010) Effect of different food on metamorphosis and survival rate of post larvae of Scylla paramamosian. Modern Fisheries Information, 25, 25-27. 